\title{
CEWP 20-01
}

\section{Unemployment Effects of Trade with a Low-Wage Country: A Minimum-Wage Model with Sector-Specific Factors}

\author{
Richard A. Brecher and Zhihao Yu \\ Carleton University
}

March 2020

\section{CARLETON ECONOMICS WORKING PAPERS}
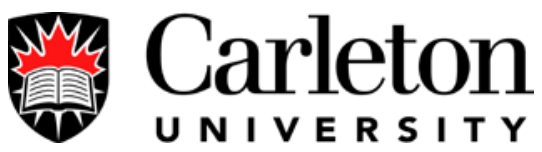

Department of Economics

1125 Colonel By Drive

Ottawa, Ontario, Canada

K1S 5B6 


\title{
UNEMPLOYMENT EFFECTS OF TRADE WITH A LOW-WAGE COUNTRY: A MINIMUM-WAGE MODEL WITH SECTOR-SPECIFIC FACTORS
}

\author{
Richard A. Brecher and Zhihao Yu* \\ Department of Economics \\ Carleton University \\ 1125 Colonel By Drive \\ Ottawa ON K1S 5B6 \\ Canada
}

March 2020

\begin{abstract}
$\underline{\text { Abstract }}$
Contrary to conventional wisdom, this paper shows that a high-wage economy can paradoxically reduce its level of aggregate unemployment by engaging in international trade with a low-wage country. We demonstrate this possibility after introducing a minimum wage into the basic specific-factor model (with immobile capital and mobile labor), even though the opposite result is known to arise in the longer-run framework of the standard Heckscher-Ohlin-Samuelson model (with both inputs mobile). Our result provides a cautionary note for public-policy discussions that promote trade barriers as a way to reduce unemployment.

JEL Classification Code: F16
\end{abstract}

Key Words: Trade, Unemployment, Minimum wage, Sector-specific factors

*Email: richard.brecher@ carleton.ca, zhihao.yu@ carleton.ca. Telephone: 613-520-2600, extension 3765 (Brecher), 3763 (Yu). We thank Till Gross for helpful discussions. 


\section{$\underline{1 . \text { Introduction }}$}

According to our main result, international trade with a low-wage foreign country may paradoxically reduce aggregate unemployment in a high-wage home country. This result runs contrary to the conventional view in public-policy discussions, which typically express fears of a trade-induced net increase in joblessness at home.

Such fears do have some theoretical support. ${ }^{1}$ Building on Brecher's (1974) analysis of minimum-wage unemployment in a two-good two-factor model of the Heckscher-OhlinSamuelson (HOS) variety, Davis (1998) considers a "benchmark case" of two identical countries with the same factor endowments, production technologies and homothetic preferences. He then imposes a minimum wage at home, and demonstrates that the introduction of world trade will necessarily increase (actually double) the level of home unemployment. Intuitively, its higher autarkic wage gives the home country a comparative advantage in the capital-intensive good, implying a reduced demand for home labor when trade is allowed to occur. Since this reduction cannot drive the wage below its minimum level, national employment must fall instead.

To allow for the opposite possibility, we relax the long-run HOS assumption that both inputs are perfectly mobile between industries of each country. Our shorter-run analysis assumes instead that only labor enjoys intersectoral mobility, while each industry has a given amount of sector-specific capital that is unable to relocate elsewhere in the economy. Thus, we use what is called the "specific-factor" or "Ricardo-Viner" model of Jones (1971) and Samuelson (1971),

\footnotetext{
${ }^{1}$ As for empirical support, the evidence is inconclusive. For example, see Feenstra and Sasahara's (2018) response to a number of papers, including Acemoglu, Autor, Dorn, Hanson and Price (2016).
} 
respectively. When a minimum wage is imposed at home within this model, a trade-induced reduction in unemployment becomes possible, as demonstrated below. ${ }^{2}$

The minimum-wage constraint could be due to a variety of institutional arrangements, such as social custom, labor unions or government legislation. This constraint is convenient for present purposes, because it is arguably the simplest mechanism for introducing the possibility of unemployment. ${ }^{3}$

Section 2 sets up the basic model, which is analyzed in section 3. The concluding section 4 summarizes the paper.

\section{Model}

Aside from the minimum wage at home, both countries are perfectly competitive. In each industry of an economy, every firm has the same production function, which is first-degree homogeneous and strictly quasi-concave. All consumers within a country have the same preferences, described by a homothetic utility function.

Technology in the home country is described as follows:

$$
X_{i}=F^{i}\left(K_{i}, L_{i}\right)=L_{i} F^{i}\left(K_{i} / L_{i}, 1\right) \equiv L_{i} f_{i}\left(k_{i}\right), \quad i=1,2,
$$

\footnotetext{
${ }^{2}$ For effects of international trade on minimum-wage unemployment in a hybrid of the HOS and specific-factor models, see Batra and Beladi (1998) who assume two mobile factors and a third input that is confined to a single industry. However, under their small-country assumption, the foreign economy is represented only by a fixed set of product prices, in which case it is not possible to make our key distinction between high- and low-wage countries.

${ }^{3}$ For other such mechanisms, see Davidson and Matusz (2004, chap. 3).
} 
where $X_{i}$ is the output of good $i ; K_{i}$ denotes the input of (sector-specific) capital in industry i; $L_{i}$ represents the amount of (mobile) labor employed in this industry; and $k_{i} \equiv K_{i} / L_{i}$. Since each production function $F^{i}$ exhibits constant returns to scale, with marginal products that are positive but diminishing, $f_{i}^{\prime}\left(k_{i}\right) \equiv d f_{i}\left(k_{i}\right) / d k_{i}>0>f_{i}^{\prime \prime}\left(k_{i}\right) \equiv d f_{i}^{\prime}\left(k_{i}\right) / d k_{i}$.

Because the rate of return to capital in each sector is perfectly flexible,

$$
K_{i}=\bar{K}_{i}, \mathrm{i}=1,2
$$

where $\bar{K}_{i}$ stands for the fixed endowment of this factor in industry $i$. On the other hand, since a minimum wage may (if high enough) lead to unemployment,

$$
L \leq \bar{L}
$$

where $L$ and $\bar{L}$ are labor's total employment $\left(L_{1}+L_{2}\right)$ and fixed endowment, respectively.

Assuming that firms maximize profits, we have the usual marginal-productivity conditions, as follows:

$$
\begin{aligned}
& r_{i}=\partial F^{i}\left(K_{i}, L_{i}\right) / \partial K_{i}=f_{i}^{\prime}\left(k_{i}\right), \quad i=1,2, \\
& w_{i}=\partial F^{i}\left(K_{i}, L_{i}\right) / \partial L_{i}=f_{i}\left(k_{i}\right)-k_{i} f_{i}^{\prime}\left(k_{i}\right), \quad i=1,2,
\end{aligned}
$$

where $r_{i}$ represents the real rental rate of capital in industry $\mathrm{i}$; and $w_{i}$ denotes labor's real wage rate in terms of good i. Given that labor is perfectly mobile between sectors,

$$
p w_{1}=w_{2}
$$

where $p$ is the relative price of the first good in terms of the second. 


\section{Analysis}

In Figure 1, before imposition of a minimum wage, the home economy produces along the full-employment production-possibility frontier $\mathrm{AB}$, drawn for $\bar{K}_{1}$ and $\bar{K}_{2}$ units of capital plus $\bar{L}$ units of labor. Where this frontier is tangent to a community indifference curve at point $\mathrm{C}$, equilibrium occurs when the country is in autarky; and $\tilde{p}$ (equal to minus the slope of the tangent at this point) is the autarkic value of $p$.

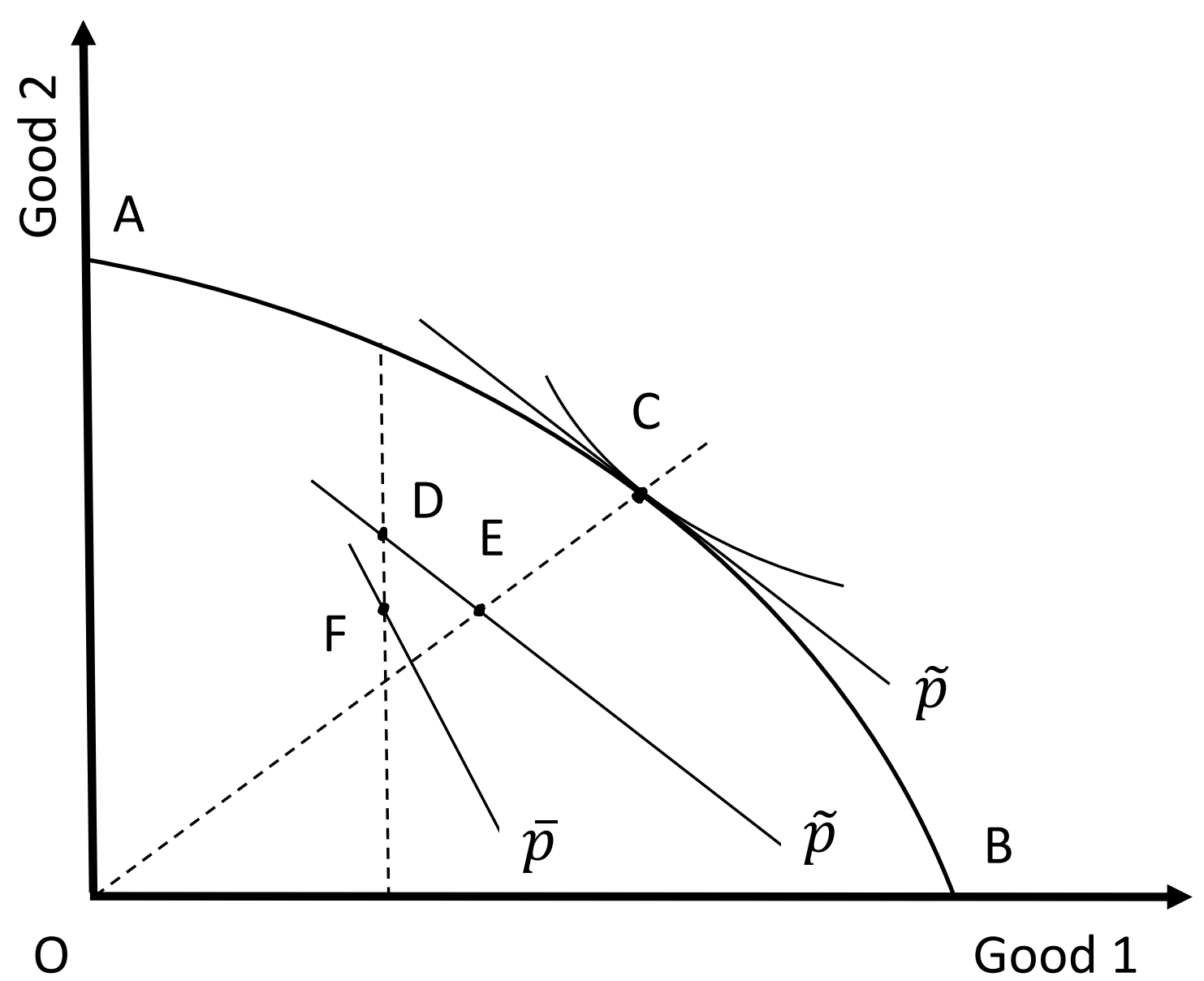

Figure 1 
Now impose a minimum wage, assumed to be the same for all workers, regardless of where they are employed. Suppose that this minimum is specified in units of (say) good 1, at a level of $\bar{w}_{1}$, which exceeds the initial (autarkic) value of $w_{1}$. (As explained below, if the minimum wage were specified instead in terms of the second good, similar results would hold, mutatis mutandis.) Then, if we temporarily hold the product-price ratio constant at its initial level $\tilde{p}$, $w_{2}$ must rise in the same proportion as $w_{1}$, to keep (6) satisfied. Consequently, both $L_{1}$ and $L_{2}$ decrease, given (5) and diminishing marginal productivity. Thus, both outputs fall to the levels associated with (say) point D in Figure 1. (Although this shows the case in which $X_{2} / X_{1}$ rises, the actual direction of change in this ratio is governed by a condition derived below.) At the same time, demand falls to point $\mathrm{E}$, which lies on the $\tilde{p}$ line through production point $\mathrm{D}$ (for a balanced budget) and on the dashed ray OC (given the homothetic-preferences assumption).

Since point $\mathrm{E}$ lies southeast of $\mathrm{D}$, there is an excess demand for good 1 (and excess supply of good 2) at the initial price ratio $\tilde{p}$. To clear this excess in the absence of international trade, $p$ must rise to (say) $\bar{p}$. With this rise in the relative price of the first good, $L_{1}$ remains unchanged by (2) and (5), since $w_{1}$ is fixed by the minimum wage $\bar{w}_{1}$. Thus, $X_{1}$ is also constant, implying that production stays on the dashed vertical line through point D. Also by (2) and (5) in light of (6), $L_{2}$ and hence $X_{2}$ decrease, thereby lowering $X_{2} / X_{1}$. Correspondingly, because indifference curves are convex to the origin, $C_{2} / C_{1}$ rises; where $C_{i}$ represents consumer demand for good $\mathrm{i}(=1,2)$. When $p$ falls from $\tilde{p}$ to $\bar{p}$, we have $X_{2} / X_{1}=C_{2} / C_{1}$, with production and consumption coinciding at point $\mathrm{F}$. At this point of autarkic equilibrium, a 
community indifference curve (not shown) is tangent to the (undrawn) production-possibility frontier for $\bar{K}_{1}$ and $\bar{K}_{2}$ units of capital plus less than $\bar{L}$ units of labor.

Although the minimum-wage constraint is specified in terms of good 1, imposing this constraint raises the autarkic value of not only $w_{1}$ (by assumption) but also $w_{2}$ in the case depicted by Figure 1, as the autarkic $p$ increases (from $\tilde{p}$ to $\bar{p}$ ) in (6). ${ }^{4}$ Thus, the minimum wage raises the utility of each employed worker, while reducing national welfare below the level represented by the community indifference curve through point $\mathrm{C}$, as the equilibrium shifts to point F.

Now introduce a foreign country, which has a perfectly flexible wage and hence full employment, but is otherwise identical to the home country. The foreign country is thus in autarkic equilibrium at point $\mathrm{C}$. Therefore, before the introduction of international trade, the relative price of good 1 is higher at home than abroad, since $\bar{p}>\tilde{p}$. This difference indicates that the foreign and home countries have a comparative advantage in the first and second goods, respectively.

When free trade is allowed to occur, each country will export (import) its good of comparative advantage (disadvantage), and the world's product-price ratio will reach an

${ }^{4}$ If point $\mathrm{D}$ were below the (dashed) ray OC, implying that $\bar{p}<\tilde{p}$, we could still show (by a somewhat more elaborate proof) that the minimum wage increases both $w_{1}$ and $w_{2}$. In both cases, since $w_{1}$ and $w_{2}$ do not move in opposite directions when the product-price ratio changes, our minimum-wage version of the specific-factor model does not exhibit what Ruffin and Jones (1977) call the "neoclassical ambiguity" in the original (flexible-wage) version of this model. 
equilibrium value that lies strictly between $\tilde{p}$ and $\bar{p}$. Thus, when free trade replaces autarky, $p$ falls (rises) in the home (foreign) country.

This fall in $p$ at home leaves $L_{1}\left(\equiv \bar{K}_{1} / k_{1}\right)$ unchanged, since the minimum wage (specified in terms of the first good) fixes the capital/labor ratio in sector 1, via (5). At the same time, the home value of $L_{2}$ rises, by (5) and (6). Thus, the home country experiences a rise in total employment $\left(L_{1}+L_{2}\right)$ when free trade is introduced.

To derive the necessary and sufficient condition for the case depicted in Figure 1, recall that this case arises if and only if imposition of the minimum wage raises $X_{2} / X_{1}$ when the productprice ratio is held constant at $\tilde{p}$. A rise in this output ratio requires that the (negative) elasticity of $X_{i}$ with respect to $w_{i}$ be greater (in algebraic value) for the second good than the first. (Because the product-price ratio is being held constant for this procedure, recall that $w_{2}$ undergoes the same proportionate change as $w_{1}$.) In other words, we need to have $e_{2}>e_{1}$, where $e_{i} \equiv\left(d X_{i} / d w_{i}\right) w_{i} / X_{i}(<0)$ for $\mathrm{i}=1,2$. If this elasticity condition is satisfied, the introduction of free trade raises total employment of the high-wage economy (with the minimum wage).

It is straightforward to verify that

$$
e_{i}=-\sigma_{i} \alpha_{i}, \mathrm{i}=1,2,
$$

where $\sigma_{i} \equiv\left[d k_{i} / d\left(w_{i} / r_{i}\right)\right]\left(w_{i} / r_{i}\right) / k_{i}$, which denotes the elasticity of technical substitution in industry $\mathrm{i}$; and $\alpha_{i} \equiv w_{i} L_{i} / r_{i} K_{i}$, which is the ratio of labor's income to capital's income in this 
industry. ${ }^{5}$ Thus, we have the following result.

Proposition 1: When free trade is introduced, the high-wage (home) country will have a rise or fall in total employment (via a fall or rise in unemployment) if and only if $\sigma_{1} \alpha_{1}>\sigma_{2} \alpha_{2}$, respectively.

If the minimum wage were re-specified in terms of the second good (rather than the first), the inequalities in Proposition 1 would simply be reversed. Thus, by continuity, such a reversal could also occur if the minimum wage were specified instead in terms of a bundle of both goods, provided that good 1 (2) has a sufficiently small (large) weight in this bundle. ${ }^{6}$

Even though trade can thus lead to more jobs, it cannot achieve full employment along the production-possibility frontier $\mathrm{AB}$ in Figure 1, according to the following argument by contradiction. With both countries operating on this frontier at the free-trade product-price ratio,

${ }^{5}$ First use (1), (2) and (5) to obtain $e_{i} \equiv\left(d X_{i} / d w_{i}\right) w_{i} / X_{i}=\left(d X_{i} / d L_{i}\right)\left(d L_{i} / d w_{i}\right) w_{i} / X_{i}$ $=\left(w_{i} L_{i} / k_{i}^{2} f_{i}^{\prime \prime}\right) w_{i} / X_{i}=w_{i}^{2} / k_{i}^{2} f_{i} f_{i}^{\prime \prime}$. Next use (4) and (5) to get $\sigma_{i} \equiv\left[d k_{i} / d\left(w_{i} / r_{i}\right)\right]\left(w_{i} / r_{i}\right) / k_{i}$ $=\left[d\left(w_{i} / r_{i}\right) / d k_{i}\right]^{-1}\left(w_{i} / r_{i}\right) / k_{i}=-\left(w_{i} / k_{i}\right) r_{i} / f_{i} f_{i}^{\prime \prime}$. Substituting this second result into the first yields (7).

${ }^{6}$ More formally, suppose that a (binding) minimum-wage constraint requires the nominal wage to equal $p_{1} b_{1}+p_{2} b_{2}$, so that a worker can (just barely) afford to buy a bundle containing $b_{1}$ units of good 1 and $b_{2}$ units of good 2. (If $b_{1}=0$ or $b_{2}=0$, the minimum wage is effectively specified in terms of the second or first good, respectively.) A reversal of the inequalities in Proposition 1 would occur if $b_{1}$ is small enough (and/or $b_{2}$ is sufficiently large). 
which exceeds $\tilde{p}$ (as noted above), each country would have an (equal) excess supply of the first good - thereby contradicting the premise that the world is in free-trade equilibrium. ${ }^{7}$

Note that the home (foreign) country has a relatively high (low) wage not only in autarky but also under free trade. This result follows immediately from the above argument that a reduction in total employment at constant product prices raises $w_{1}$ and $w_{2}$ in the same proportion. Thus, the home and foreign countries remain the high- and low-wage ones, respectively, throughout the analysis.

\section{Conclusion}

Contrary to conventional wisdom, our analysis shows that international trade with a lowwage country can paradoxically reduce the level of aggregate unemployment in a high-wage economy. We demonstrate this possibility after adding a minimum-wage constraint to the basic specific-factor model, even though the opposite result is known to arise in the longer-run framework of the standard HOS model. Our result provides a cautionary note for public-policy discussions about the unemployment effects of trade barriers, especially from a shorter-run perspective.

\footnotetext{
${ }^{7}$ In this equilibrium, home production must actually lie on the dashed vertical line (corresponding to $\bar{w}_{1}$ ), at some point above $\mathrm{F}$ and below $\mathrm{D}($ since $\bar{p}>p>\tilde{p})$.
} 


\section{$\underline{\text { References }}$}

Acemoglu, Daron, David Autor, David Dorn, Gordon H. Hanson and Brendan Price (2016), "Import Competition and the Great US Employment Sag of the 2000s", Journal of Labor Economics, 34 (S1, Part 2, January), S141-S198.

Batra Raveendra N. and Hamid Beladi (1998), "Specific Factors, Unemployment and Trade Theory", Weltwirtschaftliches Archiv, 124 (3, September), 435-444.

Brecher, Richard A. (1974), "Minimum wage Rates and the Pure Theory of International Trade, Quarterly Journal of Economics, 88 (1, February), 98-116.

Davidson, Carl and Steven J. Matusz (2004), International Trade and Labor Markets. Kalamazoo, Michigan: W. E. Upjohn Institute for Employment Research.

Davis, Donald R. (1998), “Does European Unemployment Prop Up American Wages? National Labor Markets and Global Trade”, American Economic Review, 88 (3, June), 478-494.

Feenstra, Robert C. and Akira Sasahara (2018), "The 'China Shock,' Exports and U.S. Employment: A Global Input-Output Analysis”, Review of International Economics, 26 (5, November), 1053-1083.

Jones, Ronald W. (1971), “A Three-Factor Model in Theory, Trade, and History, in Trade, Balance of Payments and Growth: Papers in International Economics in Honor of Charles P. Kindleberger (edited by Jagdish N. Bhagwati, Ronald W. Jones, Robert A. Mundell and Jaroslav Vanek), 3-31. Amsterdam, The Netherlands: North-Holland Publishing Company.

Ruffin, Roy and Ronald Jones (1977), "Protection and Real Wages: The Neoclassical Ambiguity", Journal of Economic Theory, 14 (2, April), 337-348.

Samuelson, Paul A. (1971), “Ohlin Was Right”, Swedish Journal of Economics, 73 (4, December), 365-384. 